\title{
ONTOLOGIA E METAPSICOLOGIA: CONSIDERAÇÕES SOBRE O DUALISMO PULSIONAL
}

\author{
Oswaldo Giacoia Junior*
}

Pode-se tomar atualmente como um desiderato de Freud isento de dúvidas, que sempre houve, de parte dele, uma profunda inclinação pela filosofia, tanto em razão do interesse profundo e sólido que o vinculava ao ambiente intelectual da Viena de seu tempo, como também, no que respeita à Filosofia, em especial, pela profunda influência exercida sobre jovem Freud por Franz Brentano. A Filosofia sempre constituiu um campo de questões que se impunha pela sua própria relevância, de modo que uma certa atitude ambivalente de Freud pode ser considerada, por vezes, como oscilação aproximando domínios teóricos que, em termos da divisão acadêmica, seriam contrastáveis até ao ponto do distanciamento. Sintomático e emblemático, a respeito dessa ambiguidade, é o testemunho mais que sincero de Freud ao amigo Fliess, a respeito da atração já precoce pela filosofia.

Pois bem, o que disse Freud para Fliess sobre a filosofia, no momento crucial de invenção da psicanálise? De maneira curta e grossa Freud afirmou que estava finalmente realizando o seu desejo de ser um filósofo com a invenção da psicanálise. Ao lado disso, enunciou ainda, para o espanto dos leitores, que nunca tivera talento para

\footnotetext{
* Doutor pela Freie Universität Berlin (Alemanha), professor livre-docente do Departamento de Filosofia da Universidade Estadual de Campinas (Unicamp), e pesquisador do CNPq. E-mail: ogiacoia@hotmail.com.
} 
$|124|$

Ontologia e metapsicologia: Considerações...

a terapêutica, apesar de sua atividade médica. Espanto relativo, seguramente. Isso porque Freud teve uma formação inicial como pesquisador em anatomia do sistema nervoso, a qual teve de abandonar por falta de recursos financeiros, dedicando-se então à clínica neurológica. Portanto, no contexto de constituição da psicanálise, Freud aproximava esta da filosofia e a afastava da medicina. Enfim, a psicanálise nada tinha a ver com a prática médica e não tinha qualquer pretensão terapêutica, estando bem mais próxima da filosofia (Birman, 2003, p. 12).

O elemento fundamental nesse "caso" é que Freud concebe seus trabalhos teóricos em termos de "metapsicologia", a saber, como uma consistente espécie de superestrutura teórica para investigações com embasamento empírico. Não se pode ignorar que "a palavra metapsicologia é evidentemente derivada da palavra metafísica. Ao denominar o saber teórico da psicanálise numa derivação imediata e incontornável, da palavra metafísica, Freud identifica naquela algo que a aproximaria desta. Mas o que poderia tangenciar a psicanálise com o saber da metafísica? Não parecem existir dúvidas a respeito disso: a psicanálise seria um saber fundado na interpretação e no que esta implica, qual seja, o psiquismo seria construído em torno dos conceitos de sentido e significação, na medida em que a interpretação apenas seria possível se estivesse remetida ao mundo do sentido como o seu correlato (ibidem, p. 45).

Como é sabido, divide-se a metafísica em ontologia geral, a parte fundamental da metafísica, que se ocupa com os predicados universais do ser, abrangendo as predicações elementares de todos os objetos da experiência possível, como, por exemplo, aquilo que pode ser atribuído a todo e qualquer ente, como qualidade, quantidade, relação, identidade, diferença, etc. Além da metafísica geral, há também a doutrina tradicional da metafísica especial, correspondendo a domínios de objetos que não podem ser dados na experiência, nem atual nem possível, mas que não são também da mesma ordem que os predicados mais gerais de todos os entes. A metafísica especial divide-se, de conformidade com seus objetos, 
em Teologia (ciência de Deus), Cosmologia (ciência do mundo, ou do cosmos) e Psicologia (ciência do Si-Próprio, da Consciência de Si, ou da Alma).

Ora, se uma vez que podemos admitir uma relação entre o projeto de metapsicologia e os interesses cognitivos da Metafísica, então a Psicanálise tem também de supor uma ontologia como dimensão necessária do conjunto de seu edifício teórico, a saber, um domínio de entidades fundamentais, que constitui a base teórica do saber psicanalítico. É nesse registro que se poderia inscrever a relação entre a clínica psicológica e a metapsicologia de Freud. Com base numa análise imanente de Além do Princípio do Prazer, em comparação com Totem e Tabu, esse trabalho procura demonstrar que o dualismo entre pulsões, tal como Freud os concebe na oposição entre pulsões de vida e de morte, pode ser caracterizado como a base ontológica da Metapsicologia freudiana e, por conseguinte, também de o estrato fundamental da superestrutura teórica da Psicanálise.

Para tornar plausível essa hipótese de interpretação, tomo como ponto de partida um dos principais resultados da especulação levada a efeito por Freud em Além do Princípio do Prazer: a asserção, por Freud, de uma analogia constatável entre os jogos infantis, a neurose traumática, os casos de "eterno retorno do mesmo" e os fenômenos de transferência observados em situação analítica - todos eles denotando uma compulsão a repetir vivências de desprazer, que derroga o domínio irrestrito do princípio do prazer sobre o psiquismo. Assim, a compulsão à repetição atestaria o caráter coercitivo, indestrutível, próprio do elemento pulsional. Ora, em face disso, impõe-se a pergunta a respeito da relação entre o elemento pulsional e a coerção a repetir, de modo que, a partir desse questionamento, apresenta-se uma pista na direção do que Freud denomina um caráter desconhecido das pulsões, talvez mesmo de toda vida orgânica.

Levando-se às últimas consequências esse insight, seus resultados tornariam irrecusável a conclusão de acordo com a qual toda pulsão é uma força inerente ao ser vivo, cuja meta fundamental consistiria em restaurar um estágio anterior de 
|126|

Ontologia e metapsicologia: Considerações...

desenvolvimento do organismo que este foi obrigado a abandonar por pressão de circunstâncias exteriores; trata-se de um impulso tendente à reprodução de um estágio evolutivo pretérito. Toda pulsão partilharia, pois, dessa mesma característica essencial, a saber, toda pulsão é uma espécie de elasticidade ou inércia orgânica, um modo de manifestação da força inercial inerente à vida de qualquer organismo (cf. Freud, 1982, Band III, p. 247).

É certo que Freud partilha de certos compromissos epistemológicos próprios ao positivismo e à concepção vigente de ciência no início do século XIX. Em face desses pressupostos admitidos, quando temos em mente Para Além do Princípio do Prazer, torna-se imprescindível buscar uma legitimação para a especulação metapsicológica no campo das ciências epistemologicamente atestadas, como, por exemplo, a biologia. Um tal recurso validaria a hipótese concernente à existência de uma pulsão de morte, como componente de toda vida orgânica.

A esse respeito, é preciso manter presente que, de acordo com o programa epistemológico seguido por Freud, o essencial do procedimento metodológico empregado em Para Além do Princípio do Prazer consiste na derivação dos fenômenos a partir de um elemento que permita encadear sistematicamente os fatos, cuja explicação se busca, remontando a um ponto originário servindo de âncora explicativa à série completa dos fenômenos estudados - analogamente ao que ocorre com as séries causais de que se ocupam as ciências da natureza.

Para provimento dessa condição epistemológica, Freud recorre a relações sistemáticas de analogia estrutural e funcional, observáveis entre séries de fenômenos dados na experiência em aparente desconexão. Procedimento que guarda estreita relação com aquele empregado em outras investigações especulativas de Freud, por exemplo em Totem e Tabu, que permite apreender o ganho epistemológico possibilitado pelas construções auxiliares metapsicológicas.

Em 1913, por ocasião de Totem e Tabu, Freud também procurava legitimação teórica para suas especulações nos estudos de antropologia e biologia daquela época e, combinando-os a 
partir de uma perspectiva nuclear, advinda da Psicanálise, ponderava: a derivação psicanalítica permite ressignificar os fenômenos do totemismo a partir da interpretação antropológica da refeição totêmica, conectada à hipótese de Darwin sobre o estado originário da horda primitiva. A interpretação metapsicológica, nesse caso, ensejaria uma possibilidade que cumpre uma função heurística fundamental.

Enriquecida dessas contribuições, a perspectiva metapsicológica ensejaria uma compreensão mais profunda a respeito desses fenômenos, a formulação de uma hipótese que pode parecer "fantástica" (reconhece Freud), mas que oferece uma vantagem insubstituível, que consiste em estabelecer uma até então insuspeitada unidade sintética entre séries isoladas de fenômenos, com base em relações de analogia. Esse mesmo ganho heurístico é especialmente visado e reproduzido, em 1920, com as hipóteses especulativas de Além do Princípio do Prazer.

Em busca de uma correlação fundada em analogia, Freud empreende uma retomada da descrição tópica e da função do sistema Percepção-Consciência no interior do aparelho mental, que, como o reconhece o próprio Freud, tem sua plausibilidade sustentada nos estudos de anatomia cerebral. Esse primeiro passo metapsicológico pavimentará o caminho para a asserção de uma tese a respeito da necessidade prévia da ligação, a ser entendida como condição a ser admitida para a instalação e funcionamento do princípio do prazer.

Em seguida, Freud efetua a derivação do princípio do prazer tendo por referência o princípio físico de constância, extraindo dessa derivação a inteligibilidade da tarefa imposta ao aparelho psíquico de reduzir as quantidades de energia ou excitação afluentes em seu interior (ou mantê-las num limiar constante de excitação) como princípio funcional do aparato anímico, cuja meta otimizada seria a manutenção das perturbações o máximo possível no limiar do grau zero de aporte de energia (o princípio do Nirvana).

Ora, como o proto-estado de repouso necessariamente correspondente a esse grau zero de excitação não pode ser outro, com toda evidência, senão aquele anterior ao incremento de estimulação de forças eletroquímicas, que deu origem ao 
|128|

Ontologia e metapsicologia: Considerações...

surgimento da vida na matéria inanimada, segue-se daí que o optimum resultante do funcionamento do princípio do prazer seria idêntico à meta final de toda pulsão: o restabelecimento de um estado anterior de repouso do qual o organismo foi arrancado pela complexificação das condições presentes no mundo ao redor, de modo que todo impulso seria essencialmente caracterizado por uma tendência regressiva.

Não há como não reconhecer, portanto, que os resultados parciais desse périplo especulativo transtorna todas as ideias tradicionais a respeito do telos (da finalidade) da vida - entendida como movimento de crescente aperfeiçoamento, complexificação e evolução de suas formas. Os resultados alcançados na especulação metapsicológica ensejam, antes, a lamentável conclusão de que a meta final de todo impulso é a redução ao grau zero de quantidades de excitação no organismo - ou seja, a reprodução de um estado orgânico anterior à afluência das correntes de estímulo, o que mostra que a morte (a saber, o ideal de completa descarga de toda energia afluente) é a meta, ao mesmo tempo, original e derradeira da vida.

Uma vez respaldadas tais consequências, torna-se imperioso, então, procurar uma indispensável legitimação junto à biologia para afirmar o caráter ontologicamente originário da morte em relação à vida, uma vez que o elemento pulsional seria o signo de uma inscrição da tendência à morte no coração do vivo. Ou, numa formulação ainda mais radical, faz-se necessário recorrer à biologia para garantir a plausibilidade da tese concernente à prioridade ontológica da morte sobre a vida. A partir da teoria que vincula o princípio do prazer à natureza regressiva do elemento pulsional, manifestada nos fenômenos de compulsão à repetição; ou ainda, como sustentar a hipótese de uma pulsão de morte, na medida em que uma forte plausibilidade pode ser atribuída a uma versão minimalista dessa tese concernente à pulsão em geral: cada pulsão seria uma permissão negativa por parte da biologia, que consistiria em constatar sua não inviabilidade nos marcos teóricos da ciência biológica.

De conformidade com tais exigências, tudo se processaria num plano essencialmente ontológico: se toda pulsão tem um caráter 
regressivo, seu sentido consistiria, então, no restabelecimento de um estado anterior de desenvolvimento do organismo. Ora, dentre seus estados, considerado logicamente, o primeiro não poderia ser dado a não ser pela primeira perturbação ou o aporte originário de energia eletroquímica que produziu a passagem do inorgânico ao orgânico - tão misteriosa quanto se queira -, assim como do mundo mineral para o vegetal-animal.

Sendo assim, se a natureza regressiva da pulsão remete para uma tendência a restaurar o grau zero de excitação, então seu ponto originário seria o retorno ao inorgânico, ou seja, a morte - sendo esta, pois, o elo mais recuado e originário da vida orgânica.

Daí o extraordinário valor heurístico do recurso hipotético feito por Freud à tese biológica de Weismann acerca da virtual imortalidade dos organismos unicelulares. Se a teoria de A. Weismann é correta, se ele tem razão suficiente para afirmar que as formas elementares de vida, como os protozoários (organismos unicelulares), são virtualmente imortais, então partiria do campo da ciência biológica um veto poderoso à hipótese especulativa que joga com a precedência ontológica da morte sobre a vida orgânica - veto que alcançaria, portanto, a possibilidade de asserir a existência originária de uma pulsão de morte, pois esta seria um acontecimento secundário, ocorrido no curso da vida, derivado da complexificação das formas vivas, a partir do surgimento dos organismos multicelulares - em particular da divisão e especialização entre células somáticas e germinativas.

Um novo ponto de vista é introduzido pela ponderação dos resultados obtidos a partir da crítica biológica, que derroga in totum os resultados teóricos das experiências de Weismann. Essa crítica põe em dúvida a consistência da hipótese de se investigar a originariedade da morte a partir das formas elementares de organismos. Sua organização incipiente e primitiva poderia ocultar condições e processos que só adquiririam visibilidade em formas morfológicas mais complexas. Como argutamente observa Mezan: "Depois de examinar as hipóteses então vigentes na Biologia acerca da 'imortalidade' dos protozoários, Freud conclui que o exame empírico da questão é irrelevante para estabelecer 
|130|

Ontologia e metapsicologia: Considerações...

ou falsificar o princípio que propõe, pois, como em outros casos, tendências opostas poderiam estar camufladas sob a indiferenciação do organismo unicelular, só surgindo com plena evidência em seres vivos mais organizados, cujas funções se houvessem dispersado por vários sistemas e órgãos. O caráter transcendental da pulsão de morte fica assim confirmado, uma vez que nenhum sistema específico tem a seu cargo a efetivação desta finalidade pulsional: trata-se do fundamento de outros fenômenos, não de mais um entre eles" (Mezan, 1991, p. 262).

Tendo em vista esses elementos, Freud recorre a um procedimento analógico para explorar metapsicologicamente a semelhança entre a distinção weismanniana entre células somáticas e plasma germinal, por um lado, e a separação psicanalítica entre instintos de morte dos instintos de vida, por outro lado, numa ação direcionada por outra analogia biológica, desta feita tomando como pares analógicos os processos vitais baseados em pulsões de vida e pulsões de morte e as funções biológicas de assimilação e dissimilação, para dar conta da explicação buscada.

Desta vez, recorrendo à teoria preeminentemente dualística sustentada também por E. Hering a respeito da natureza e da dinâmica dos impulsos, Freud distingue dois tipos de processos constantemente em ação na substância viva, operando em direções contrárias: um deles de caráter construtivo ou de assimilação; e um processo destrutivo ou de desagregação. Com base em inferências analógicas, Freud aproxima, ao ponto de chegar mesmo à identificação dessas duas direções tomadas pelos processos vitais com a atividade dos dois impulsos ou pulsões fundamentais do organismo em geral: as pulsões de vida e as pulsões de morte (cf. Freud, 1982, Band III, p. 260).

Essa analogia entre os instintos de vida e de morte, apoiada nas funções biológicas de assimilação e dissimilação, remete, por seu turno, a uma analogia ainda mais ousada, a saber aquela remetendo à dualidade pela qual Freud é remetido ao ancoradouro teórico da metafísica schopenhaueriana, em cujo marco o impulso sexual (e de autoconservação) é manifestação da vontade de viver, 
enquanto que o verdadeiro resultado, e mesmo a meta definitiva da vida, é a morte.

Essa transposição da analogia biológica para a metafísica impele a especulação a dar um novo e importante passo avante, em termos das especulações freudianas. Trata-se, pois, de levar avante a investigação desses resultados à luz da contribuição essencialmente psicanalítica proporcionada pela teoria da libido, um exame que, em Para Além do Princípio do Prazer é mais uma vez levado a efeito por meio do recurso ao pensamento por analogias. Nesse caso específico, a analogia se estabelece tomando como termos, de um lado, a relação entre a energia psíquica da libido e o objeto sobre o qual essa energia é investida; por outro lado, a relação citológica entre células somáticas de tipo diverso.

Uma analogia reconhecida entre o dualismo das pulsões e a economia libidinal das células orgânicas permite o estabelecimento de um novo paralelo, desta vez explorando a dynamis das pulsões sexuais ou de vida - cuja atividade tem como meta a ligação em unidades sempre maiores. A propósito, o símbolo escolhido por Freud para os impulsos da sexualidade é a divindade mítica Eros - tal como descrito pelos filósofos e poetas - empenhado em instituir unidades a cada vez mais amplas, do organismo individual, passando pela família, até a grande união da cidade. O contraponto do erótico seria a tendência, igualmente presente em todo organismo vivo, de dissolver novamente a unidade orgânica e agregativa de suas partes nos elementos físico-químicos inanimados que ingressam em sua composição original.

Ora, essa identificação coloca a especulação metapsicológica diante da dificuldade, aparentemente intransponível, que força Freud a passar em revista sua teoria das pulsões, a partir de seus movimentos iniciais. Uma teoria que Freud faz questão de caracterizar como essencialmente dualistas. Trata-se de um dualismo que, nos termos da reconstituição de Freud, traduzia-se inicialmente na oposição entre pulsões do Eu (impulsos de autopreservação, subsumidos sob a metáfora da Fome) e pulsões sexuais (cuja energia, voltada sobretudo para a 
$|132|$

Ontologia e metapsicologia: Considerações...

sexualidade e reprodução, era denominada libidinal) investidas em objetos diferentes do próprio Eu. Tratava-se da versão psicanalítica da mais inicial contradição entre fome e sexualidade, posteriormente modificada pelas descobertas propiciadas pelo aprofundamento dos estudos a respeito do narcisismo, sem, no entanto, abrir mão de um irredutível dualismo ontológico.

A exploração especulativa do conceito de narcisismo representou um risco considerável de dissolução desse dualismo pulsional, do ponto de vista da coerência e consistência da ontologia com a qual tem de operar a metapsicologia freudiana. Freud não cessa de reconhecer que sua ontologia das pulsões é eminentemente dualista; e, no entanto, a extensão da libido que termina por açambarcar inclusive as pulsões do "Eu", com, por exemplo, o impulso de conservação, parece ter como consequência um comprometimento do dualismo pulsional, levando a metapsicologia freudiana para uma proximidade de um limiar teórico que ameaça fazer concessões lógicas ao monismo analítico de Carl Gustav Jung. Como se sabe, a Psicanálise na versão jungiana é fundada, do ponto de vista pulsional, num monismo que identifica a libido com energia psíquica.

Para Freud, no entanto, suas novas descobertas, trazidas à luz com os estudos sobre o narcisismo primário, demonstram o contrário de um dualismo: em primeiro lugar, elas autorizam a inferência de acordo com a qual a libido pode investir e retirar seu investimento dos objetos a que se liga, do mesmo modo como tais objetos podem ser investidos sucessivamente por impulsos tanto eróticos quanto hostis. Em segundo lugar, não é mais teoricamente necessário confrontar pulsões eróticas e pulsões do Eu, pois as consequências teóricas das investigações sobre o narcisismo primário revelaram também que o Eu pode ser objeto de investimento de libido - o que se atesta clinicamente nos casos de pacientes narcísicos, ou enamorados de si; mas ainda, e esse dado é de importância capital, que o Eu é o reservatório originário de toda libido.

No curso ulterior do desenvolvimento do indivíduo, parte dessa libido originalmente narcísica é subtraída do Eu e canalizada para os investimentos de objeto. Ora, a teoria da evolução da 
libido individual comprova que investimentos libidinais podem ser efetuados e retirados de seus objetos, o que vem em apoio da teses de acordo com a qual nada impede que o investimento de libido possa partir do Eu, canalizar-se para objetos diferentes dele, bem como retornar ao $\mathrm{Eu}$, o que desestabiliza a teoria da autopreservação como pulsão orgânica concorrente a Eros.

\begin{abstract}
A concepção do narcisismo primário põe em cheque a leitura da auto-preservação; eis aí um fenômeno de natureza claramente sexual, e que no entanto atua na esfera do ego, anteriormente visto como aquilo que é sustentado pelas pulsões de auto-conservação. Se Eros é aquele que liga, a mútua adesão das células somáticas pode ser vista como uma de suas manifestações, de sorte que a libido narcisista passa a ser derivada da soma das quantidades de libido contidas na totalidade das células corporais: pois o ego é sempre e em primeiro lugar um ego corporal, construído par conduzir às modificações da realidade exterior essenciais para a satisfação das necessidades básicas do organismo, como Freud não cessou de pensar desde o Projeto (Mezan, 1991, p. 262).
\end{abstract}

Na vigência da hipótese do narcisismo primário, não se pode mais cogitar razoavelmente, portanto, a oposição entre pulsões do Eu e pulsões eróticas (como se o elemento diferencial passasse pelos investimentos objetais), impondo-se uma revisão em profundidade da teoria das pulsões. Pois, suposto o narcisismo primário, não há como recusar que o próprio Eu pode ser - e efetivamente é - objeto de investimento libidinal. Disso resulta que parte dos impulsos anteriormente considerados como pulsões do Eu (ligados à antiga noção de pulsões não sexuais de autoconservação) passam a ser identificados também como eróticos ou libidinais - mesmo quando encarregados da tarefa de autopreservação. Trata-se, pois, de uma descoberta que coloca a metapsicologia diante de um problema de imensa relevância teórica: como manter o dualismo pulsional (cujo estatuto se 
|134 |

Ontologia e metapsicologia: Considerações...

pretende, como já mencionado, ontológico), se os únicos impulsos identificáveis do Eu são de natureza libinal?

Por essa razão, a consolidação teórica do conceito de narcisismo transtorna a distinção categorial inicial da teoria das pulsões, desautorizando o conflito figurado entre Eros e Ananké, ou Fome e Sexualidade - já que a distinção entre pulsões sexuais e pulsões do Ego encontra-se em suspenso, na medida em que o próprio Ego é também objeto de investimento libidinal.

A rigor, tudo indica que, a partir desse momento, seria mais correto falar em libido do Ego e libido objetal, comprometendo o dualismo, pois o Ego passa a figurar como "o grande reservatório originário da libido", a partir do qual esta é enviada para os objetos, dos quais pode também refluir de volta para o Ego. Doravante, portanto, seria mais adequado considerar um conflito originado entre a libido objetal e a libido do ego, sendo necessário confessar que as pulsões de autopreservação são também de natureza libidinal; a saber, são pulsões sexuais que, em vez de objetos externos, tomam o próprio Ego como objeto. Se, apesar disso, Freud continua sustentando uma concepção dualista das pulsões, ele só pode fazê-lo então com lastro em provas dotadas de menor poder de convencimento.

Do ponto de vista da consistência da teoria, dado o caráter manifestamente inconvincente das provas até então produzidas, seria, portanto, logicamente indispensável decidir entre os membros de uma alternativa incômoda: ou bem postular a existência de impulsos do Eu cuja natureza não é erótica, porém cuja designação precisa e direta não se pode levar a efeito - isto é, não é possível indicar qualquer dos representantes dessas instâncias pulsionais -; esta, porém, é notoriamente uma condição teoricamente precária, e no entanto indispensável para manutenção do dualismo pulsional; ou então renunciar a este e abraçar um monismo no gênero de Jung, que, como vimos, considera termos sinônimos libido e energia pulsional.

Freud mantém uma posição intransigentemente dualista, sustentando sua posição numa estratégia argumentativa desenvolvida em dois tempos. Essa estratégia o habilita para 
formular uma nova versão (ontologicamente dualista) da teoria das pulsões, mesmo enfrentando a dificuldade consistente em não poder indicar diretamente um representante puro, sem mistura, das pulsões de morte. As representações desse grupo pulsional só seriam inferíveis num campo de visibilidade em que se apresentam mais ou menos pronunciadamente fundidos ou coligados com as pulsões eróticas.

Tenhamos em vista o primeiro momento da argumentação: aqui Freud vai recorrer às observações clínicas extraídas da observação sistemática dos casos de sadismo e masoquismo. Com efeito, no sadismo e no masoquismo, embora se possa observar uma fusão entre Eros e agressividade - cujos impulsos são podem ser voltados tanto para um objeto externo quanto para o Eu -, os grupos pulsionais apresentam-se como ontologicamente distintos e antagônicos em suas metas. Com efeito, não é logicamente possível conciliar Eros-libido (cuja operação e finalidade consiste na ligação e preservação) com a destrutividade, com as tendências pulsionais hostis, cujo telos é a destruição do objeto (é preciso lembrar, por exemplo, que o sadismo predominante na fase oral do desenvolvimento da libido coincide com a real ou virtual destruição sobre o qual a energia é investida, por exemplo, os atos de mamar e morder).

Se a hipótese é plausível, e os estudos sobre o narcisismo primário revelaram que é, então pode-se estender suas consequências no sentido de supor que esse representante do grupo das pulsões não eróticas atesta sua natureza hostil portanto de pulsões de destrutivas, cuja tendência é a morte -, pois que tanto podem conduzir à destruição do objeto na fase oral, como entrar a serviço da função sexual, atuando como forças auxiliares na dominação, voltada ao propósito de assegurar a posse e desfrute sexual do objeto, embora só possa manifestar-se em fusão com Eros. Assim, reconduzindo a polaridade pulsional constatável no sadismo e no masoquismo à polaridade ontológica entre pulsões de vida e pulsões de morte - mesmo levando em conta a atenuante de que os impulsos sádicos só seriam designáveis em fusão com as pulsões eróticas -, ainda assim, a despeito da fusão, poder-se-ia apreender a natureza originariamente destrutiva de certa categoria de pulsões, cuja 
$|136|$

Ontologia e metapsicologia: Considerações...

energia não é redutível à rubrica dos impulsos encarregados da função vital erótico-libidinal de ligação.

Por intermédio desse argumento Freud garante a isonomia e a simetria ontológica entre os dois grupos pulsionais compreendidos no dualismo, sendo que o grupo das pulsões de morte manteria até mesmo uma precedência relativa sobre os representantes de Eros no que concerne ao investimento objetal da energia dos instintos libidinosos. Freud chega mesmo a cogitar como plausível que o sadismo - uma vez expulso do ego -, apontou primeiramente o caminho para os componentes libidinais do impulso sexual. Os representantes de Eros tê-lo-iam seguido na direção do investimento de objetos.

Se considerarmos, adicionalmente, como um resultado assegurado, que a eliminação das tensões ou quantidades de excitação acorrentes no sistema psíquico pode ser tomada como a meta do processo vital - tal como já aparecia nas problematizações iniciais do princípio de constância e sua modificação pelo princípio do prazer -, então essa contribuição da biologia pode ser aproveitada em termos metapsicológiacos no sentido de superar impasses teóricos. Nesse passo, o argumento de Freud retoma o fenômeno da revitalização dos organismos celulares por meio de sua esporádica mistura na forma mais primitiva da cópula entre protozoários.

De acordo com o argumento explorado em Para Além do Princípio do Prazer, a coalescência (o antecedente da união copulativa entre dois indivíduos unicelulares que se separam logo após a união, sem que qualquer divisão celular subsequente ocorra) fortalece e rejuvenesce ambos os corpúsculos. Em suas gerações ulteriores, esses organismos não evidenciam nenhum sintoma de degeneração, resistindo mais longamente aos efeitos prejudiciais de seu próprio metabolismo. Freud considera a observação desse efeito da coalescência como caso típico dos efeitos da cópula sexual: também ele representa um fator de introdução de diferenças vitais, ou o aporte de novas quantidades de estímulo ou energia orgânica. Esse resultado, no entanto, é perfeitamente compatível com a hipótese de que os processos vitais do indivíduo levariam, por razões internas, a uma eliminação das tensões 
químicas, isto é, à morte, não fora o afluxo de energias resultante da coalescência.

Em sentido inverso, a união (função típica de Eros) com a substância viva de um indivíduo diferente implica num aporte de tensões vitais, introduzindo novas "diferenças quantitativas", ou cargas energéticas cuja elevação tem de ser, em seguida, compensada (abgelebt, como escreve Freud), isto é descarregadas pelo processo vital (Freud, 1982). Verificamos, portanto, que a introdução do conceito de narcisismo primário, assim como a derivação da polaridade pulsional do investimento objetal verificado nos casos de sadismo e masoquismo nos permitem fixar novos resultados importantes, que conduzem ainda mais longe a especulação: a indiferenciação, de princípio, entre um investimento pulsional que parte do eu e se dirige aos objetos, ou que perfaz um circuito contrário, partindo dos objetos de volta para o Eu.

Sendo assim, o masoquismo - isto é, o movimento de retração das pulsões de um investimento objetal em direção ao eu - seria, com toda propriedade, um retorno, isto é, uma regressão para uma fase mais antiga da organização psíquica. Em correspondência com isso, poder-se-ia cogitar tanto de um narcisismo primário quanto de um masoquismo igualmente primário, ao qual o indivíduo retornaria sob a forma psicopatológica da perversão masoquista, em que os componentes masoquistas se separam das pulsões eróticas e tornam-se independentes, passando a dominar a vida sexual - como também se pode observar nos casos de perversão sádica.

Se, de acordo com o argumento, podemos concluir que a tendência dominante tanto da vida mental como da vida nervosa, em geral, é a tendência para reduzir, manter constante, (ou, como um optimum teórico) eliminar por descarga a tensão interna das quantidades de excitação (Princípio de Nirvana), torna-se legítima a inferência de acordo com a qual também o princípio de prazer é expressão dessa mesma tendência - conclusão que constitui uma das mais fortes razões para manter a postulação do dualismo e o reconhecimento de impulsos originários de morte atuando no interior do organismo vivo. 
$|138|$

Ontologia e metapsicologia: Considerações...

Não obstante, se a pulsão de morte deve poder afirmar-se como conceito, é preciso que dê provas de seu valor heurístico, servindo como princípio para interpretar ao menos uma parte dos fenômenos que caem sob o olhar da psicanálise. É por esta razão que Freud se vê na contingência de buscar um exemplo - não uma confirmação - da atividade da pulsão de morte (Mezan, 1991, p. 262).

Permanece, no entanto, um problema a resolver: como entender o funcionamento das pulsões de autoconservação, se a finalidade última de toda pulsão seria a destruição do organismo? Tal problema seria contornável com recurso à explicação de acordo com a qual cada organismo se esforça por evitar a perempção ocasionada por causas externas. Sendo assim, os impulsos de autoconservação asseguram que todo organismo vivo se defende das ameaças externas de destruição, com o propósito último de morrer sua própria morte, de lutar com todas as suas forças para assegurar essa possibilidade, de modo que as pulsões que integram o grupo da autopreservação deveriam ser interpretadas como a defesa da maneira própria de morrer de cada organismo, e de cada espécie orgânica. Em consequência, os impulsos aparentemente garantidores da vida seriam, em derradeira instância, desvios de duração, atalhos, satélites da morte.

Persiste, no entanto, a dificuldade de apontar na psicologia individual um representante da pulsão de morte, agora acrescida de outra adicional, não menos relevante: como enquadrar nessa explicação a tendência dos impulsos eróticos, cuja energia libidinal é investida na organização de unidades sempre mais amplas, numa trajetória que guarda semelhança com uma linha de evolução e aperfeiçoamento, distendida ao infinito?

Ora, como conciliar esse traçado evolutivo com a tendência regressiva de toda pulsão? A especulação metapsicológica se coloca, pois, em presença de outro dilema: se os impulsos eróticos se esforçam para unir os homens em organizações de uma ordem sempre mais crescente, impelindo-os para frente no sentido da vida, como verdadeiras pulsões de vida - o que encontra atestação empírica -, como atribuir-lhes um caráter regressivo, essência do 
pulsional? Qual seria o estado anterior da existência do organismo que as pulsões compreendidas no grupo dos impulsos de vida (ou sexuais) teriam por propósito restabelecer?

De acordo com o programa freudiano de pesquisa para a metapsicologia, o preço a pagar pela plausibilidadedo dualismo pulsional seria a necessária isonomia entre os grupos pulsionais, ou seja, sua comum originariedade no fenômeno da vida. Isso exige a transição necessária do plano da psicologia individual para a psicologia social. Caso contrário, sendo uma delas formação derivada e secundária, a consequência necessária seria a inevitabilidade ontológica do monismo. Se pulsões de vida e de morte não fossem impulsos originários, um deles seria inevitavelmente decorrência do desenvolvimento do outro.

Tendo levado suas especulações até esse ponto, destaca-se ainda mais o principal objetivo, e, ao mesmo tempo, compromisso teórico de Freud: levar às últimas consequências suas hipóteses metapsicológicas. Ele pretende, com elas, resolver problemas que têm sua origem e campo de incidência na prática clínica, mas que são, em sua envergadura própria, dificilmente acomodáveis nos esquemas de teoria psicanalítica até então desenvolvidos. Para reformular esses esquemas, de modo a perfazer a explicação dos fatos e a superação da crise teórica por eles suscitada, Freud é obrigado a lançar mão de recursos aparentemente heterodoxos, como as analogias com as explicações filosófico-metafísicas, ou as ficções poéticas.

Se tomarmos a sério a sugestão de Loparic, essa postura faria todo sentido no quadro do programa de pesquisa da Psicanálise praticada como ciência empírica. Trata-se de explicações metafóricas, ficções heurísticas úteis, em termos anteriormente postos em circulação por Kant, para a resolução de problemas psicopatológicos específicos. A metapsicologia seria, pois, "uma metafísica metafórica da natureza de tipo kantiano - superestrutura especulativa com fins apenas heurísticos e, por isso mesmo, não fundante" (Loparic, 2003, p. 243 ss.).

Tentamos encontrar um reforço para esse diagnóstico de Loparic ao refazer o percurso argumentativo das especulações 
| 140 |

Ontologia e metapsicologia: Considerações...

metapsicológicas à luz das as exigências teóricas do programa psicanalítico de pesquisa. As "ficções heurísticas" teriam uma função superestrutural consistente em oferecer um arcabouço teórico para o regime das analogias estabelecidas entre as séries de fenômenos ordenados. No caso de Além do Princípio do Prazer, por meio da combinação de elementos oriundos da teoria do aparelho psíquico, dos modos de funcionamento primário e secundário, dos princípios de constância e nirvana, da teoria das pulsões. Em meio às contribuições colhidas junto à biologia, à antropologia, à filosofia, à literatura, à psicologia, a contribuição psicanalítica seria capaz de lançar um raio de luz nas trevas em que se debate a perplexidade teórica.

Ora, é para esconjurar essa desorientação em meio à escuridão total que a especulação parte em busca de uma hipótese que, mesmo mítica, permitiria, depois de convenientemente iluminada pelo filtro da interpretação psicanalítica, prover uma explicação que permite cumprir uma das mais fundamentais condições a que se submete a investigação metapsicológica. Assim, metapsicologia se atreve a recorrer ao mito porque, fazendo-o, ela satisfaz uma condição incontornável que, uma vez satisfeita, supre e elo teórico faltante, e permite derivar geneticamente a origem de toda pulsão de uma necessidade de restauração de um estado anterior de coisas (Freud, op. cit. p. 68).

Uma hipótese nesse sentido, mesmo que de natureza míticofantástica, satisfaz aquela condição originária que torna possível o ordenamento integral da série dos fatos a explicar, com base num regime regrado de analogias. $\mathrm{O}$ que Freud tem em vista, nesse momento da argumentação, é a explicação mitológica que Platão atribuiu a Aristófanes no Banquete, de acordo com a qual, tendo Zeus dividido em dois gêneros seres humanos originariamente hermafroditas, as duas partes (masculino e feminino) se esforçam desde então por restabelecer a unidade originária perdida.

Recorrendo ao mito, Freud encontra um elemento originário para a ordenação dos fatos, como de princípio de inteligibilidade das analogias. É interessante observar que análogo recurso heurístico a uma hipótese "mitológica" da horda primitiva 
e do parricídio originário satisfazia idêntica condição para a especulação desenvolvida por Totem e Tabu. Neste texto, a mesma metáfora do raio de luz ${ }^{1}$ lançado pela contribuição psicanalítica figurava como estabelecendo a mediação entre as explicações antropológicas, sociológicas, filosóficas, folclóricas, etnológicas e de ciência jurídica a respeito das relações entre totem e tabu, isto é, entre moralidade, sociabilidade e religião.

Naquele caso, a Metapsicologia tornava possível a fecundação teórica da hipótese de Darwin sobre a horda primitiva pela teoria de Robertson Smith a respeito do significado da refeição totêmica. Com isso, a Psicanálise provia o ponto de vista central que permitia a compreensão de um conjunto regrado de analogias, ou, em outras palavras, a teoria do desenvolvimento da libido permitia aproximar, por analogia, o primitivo, a criança e o neurótico, bem como a psicologia social e individual, a filogênese e a ontogênese.

No caso de Além do Princípio do Prazer, a narrativa platônica psicanaliticamente interpretada (cf. Freud, 1982, Band III, p. 266 ss.). cumpre precisamente a mesma função exigida pelo programa de pesquisa: tornar plausível a tese do caráter regressivo também dos impulsos eróticos, lançando um raio de luz sobre o estado anterior de desenvolvimento do organismo que a pressão por eles compulsivamente exercida visaria restaurar: a saber, o hermafroditismo originário, uma condição da vida orgânica inequivocamente mais primitiva do que o organismo sexualmente diferenciado.

Com isso, ficaria também assegurado o elo originário que serve de base para uma ordenação da série inteira de analogias desdobradas ao longo do texto. Nos dois casos, estaríamos diante do cumprimento da mesma condição, ou seja, de encontrar o elemento originário que serve de base para uma derivação genética, bem como para instituir, heuristicamente, um regime sistemático de analogias entre séries de fenômenos até então desconectadas.

${ }^{1}$ Cf. Totem e Tabu, frase de abertura do item número 3 do capítulo IV, intitulado O Retorno Infantil do Totemismo. 
|142|

Ontologia e metapsicologia: Considerações...

Desse modo, completa-se o movimento de explicação: todas as pulsões têm em comum a mesma natureza e caráter regressivo, que, por sua vez estaria relacionada à função mais primitiva e fundamental de toda substância vida, a saber, o retorno ao repouso do inorgânico, ou seja: o princípio de Nirvana. A experiência comum atesta que o maior prazer que somos capazes de atingir, aquele resultante da satisfação sexual, está indissociavelmente ligado a uma intensa descarga de energia psíquica. Essa experiência, a que todos temos acesso, reforça a hipótese de acordo com a qual a ligação de uma quantidade de energia pulsional seria uma função preliminar, cuja finalidade consiste em preparar a quantidade de excitação para sua eliminação final (Freud, 1982, Band III, p. 264).

Nesse caso, as pulsões eróticas, ou de vida, seriam, apenas desvios permanentes no caminho da morte. Contudo, nesse percurso desviante, atuaria um poderoso fator complicador, que mantém em adiamento perene o destino final: o retorno ao inorgânico não pode ser alcançado por força de uma contradição dialética que se institui entre sua meta e o caminho para alcançá-la. Não há como negar que a atração entre os sexos, no exercício da função regressiva visando o retorno à perdida unidade originária - e assim, encetando novamente o percurso em direção ao repouso no inorgânico - é também, ao mesmo tempo, a força que impele à obtenção do contrário dessa meta: a saber, a reprodução da divisão e do caminho em direção a complexos orgânicos cada vez maiores, cuja origem está necessariamente dada com a fusão de duas células germinativas.

Desse modo, a morte final é inalcançável porque o caminho para ela é um desvio permanente: “Quando, enfim, a potência da morte é reconhecida explicitamente, quando enfim essa imantação radical é desvelada, essa atração irresistível para o vazio, para a não excitação absoluta, é nomeada, nesse instante um outro polo adquirirá uma força inusitada: $a$ vida. A junção das pulsões sexuais e das pulsões de autoconservação - Eros - vai adquirir a propriedade inquietante de ser perturbadora da ordem gélida do inorgânico. Essas "tensões" são a condição do vital desde o 
seu aparecimento e são exatamente elas que a pulsão de morte visa anular" (Monzani, 1989, p. 229).

Mesmo que esses resultados não sejam suficientes para lançar luz sobre a totalidade das questões implicadas na especulação metapsicológica, eles permitem, no entanto, articular e compreender o conjunto dos elementos implicados na montagem do problema, assim como levar a cabo uma tentativa plausível, teoricamente consistente, de solução do mesmo. Salva-se o dualismo pela prova do caráter regressivo das pulsões eróticas, assim como de sua indestrutibilidade, propriedades que podem ser tomadas como características essenciais da pulsão.

Que não seja o mesmo tipo de solução que poderia satisfazer in totum o modelo epistemológico do qual Freud parte, isso talvez possa ser debitado à natureza do objeto, a carecer de remanejamentos teóricos constantes. Mesmo assim, essa restrição não afastaria a Psicanálise freudiana de um programa de pesquisa determinado com base em um ideal de ciência, próprio de seu tempo, que descrê da onipotência, jamais, porém, da suficiência persistente e sempre retificável da sabedoria do deus Logos.

\section{Bibliografia}

BIRMAN, J. Freud - A Filosofia. Rio de Janeiro: Jorge Zahar Editor, 2003.

FREUD, S. "Jenseits des Lustprinzips". In: Werke. Studienausgabe. Ed. Alexander Mitscherlich et alii. Frankfurt/M: Fischer Verlag, Band III, 1982.

LOPARIC, Z. "De Kant a Freud: Um Programa". In: Revista Natureza Humana, v. 5, n. 1, jan./jul. 2003.

MEZAN, R. Freud. A Trama dos Conceitos, $3^{a}$ ed. São Paulo: Ed. Perspectiva, 1991.

MONZANI, L. R. Freud: O movimento de um pensamento. Campinas: Ed. da Unicamp, 1989. 